\title{
Gold-catalyzed post-MCR transformations towards complex (poly)heterocycles
}

\author{
Upendra K. Sharma ${ }^{\mathrm{a}}$, Guilong Tian ${ }^{\mathrm{a}}$, Leonid G. Voskressensky ${ }^{\mathrm{b}}$, \\ Erik V. Van der Eycken ${ }^{\mathrm{a}, \mathrm{b}, *}$
}

ataboratory for Organic \& Microwave-Assisted Chemistry (LOMAC), Department of Chemistry, University of Leuven (KU Leuven), Celestijnenlaan 200F, B-300I, Leuven, Belgium

${ }^{\text {b} P e o p l e s ~ F r i e n d s h i p ~ U n i v e r s i t y ~ o f ~ R u s s i a ~(R U D N ~ U n i v e r s i t y), ~ M i k l u k h o-M a k l a y a ~ S t r e e t ~ 6, ~ I I 7198 ~ M o s c o w, ~ R u s s i a ~}$

Post multicomponent reaction (MCR) transformations are one of the most successful methods leading to high structural diversity and molecular complexity. A wellknown MCR, the Ugi reaction typically affords a linear peptide backbone, enabling post-Ugi transformations as an elegant solution to rigidify the Ugi adduct into more drug-like species. Not surprisingly, the development of such transformations leading to new structural frameworks has expanded rapidly over the last few years. These reactions have reached an impressive level of performance and versatility, particularly in amalgamation with gold catalysis. This review outlines the developments achieved in the past decade, highlighting the modifications that are performed in a sequential or domino fashion with emphasis on major concepts, synthetic applications of the derived products as well as mechanistic aspects.

\section{Introduction}

The sequencing of multicomponent reactions (MCRs) and subsequent cyclizations is a powerful strategy for the rapid

*Corresponding author: E.V. Van der Eycken (erik.vandereycken@kuleuven.be)

\section{Section editor:}

Romano Orru - Synthetic \& Bio-organic Chemistry, VU University, Faculty of Sciences, Amsterdam Institute for Molecules, Medicines \& Systems, Organic Chemistry, The Netherlands.

construction of diverse (poly)heterocyclic scaffolds [1,2]. The central goal of diversity-oriented synthesis (DOS) is to generate structurally and stereochemically diverse molecules for biological evaluations. The idea is that broader diversity in the chemical library will lead to the generation of additional information from biological screenings. Therefore, the synthesis of complex polycyclic molecular scaffolds bearing resemblance to pharmaceutically relevant natural products has always remained an attractive proposition for synthetic chemists. The combination of multicomponent reactions (MCRs) and transition metal-catalyzed post-transformations provides an enormous capability to generate molecular complexity and diversity in a minimum number of steps $[3,4]$.

With the introduction of transition metal-catalyzed reactions as a contemporary tool in synthetic organic chemistry, a significant impact has been exerted on the syntheses of wellestablished classes of heterocycles [5,6]. Among the various metals explored, it is no surprise that gold complexes adopt a central role in post-MCR transformations [7]. Gold has always 
been perceived as the most precious metal for thousands of years. In addition, past decades have already seen a "gold rush" with a myriad of chemical transformations in both homogenous [8,9] and heterogeneous catalysis [10]. Various new reaction modes and novel reactivities have already been discovered, due to the exceptional ability of gold complexes to activate alkynes, alkenes, and allenes towards nucleophilic attack, which is quite evident from the seminal work of Hashmi, Toste, Echavarren, and others $[8,11,12]$. Scheme 1 outlines a general approach for the cyclization using various gold complexes.

This concise review will focus on post-MCR transformations performed as a separate step or in a domino/cascade fashion that have been reported in the past few years employing gold catalysis.

\section{C-C bond forming reactions}

Gold-catalyzed cyclizations of (hetero)aromatic compounds with alkyne side chains have attracted considerable attention in the last decade. In particular, intramolecular gold-catalyzed hydroarylations, cycloisomerizations and cycloadditions have offered new ways for the efficient construction of biologically relevant hetero(poly)cycles [7-12]. Indole and pyrrole containing heterocyclic motifs can be seen in various natural products and pharmaceutically relevant compounds $[13,14]$. In addition, 7-membered $\mathrm{N}$-containing rings fused with benzene or indole represent a common pattern in a plethora of alkaloids isolated from various natural sources, as well as in a significant series of pharmaceuticals. A large subclass of these compounds incorporates either the phenylethylamine or the tryptamine motif, both of them occur widely in nature. Dorel and Echavarren were the first to apply gold catalysis for the construction of the azepino[ $[4,5-b]$ indole and azocino[4,5-b]indole core [12] followed by our group [15], where in situ generated cationic gold(I)-species were found to be effective for similar transformations. Notably, this $\mathrm{AuPPh}_{3} \mathrm{Cl} / \mathrm{AgOTf}$ catalytic system was found to be an efficient replacement for our earlier reported $\mathrm{Hg}(\mathrm{OTf})_{2}$-catalyzed intramolecular alkyne hydroarylation reactions [16] for the synthesis of variously substituted azocino[4,5-b]indoles. However, one of the main problems associated with these reactions was the synthesis of the starting materials, which required tedious multistep procedures along with the generation of ample waste. Moreover, from a diversity-oriented synthesis point of view, these chemical methods were also not sustainable.

In this context, isocyanide-based multicomponent reactions [4] (IMCRs) have been widely explored because of their unmatched capability to generate molecular complexity and diversity to expand the chemical space. From the past twenty years, the Ugi four-component reaction (Ugi-4CR) [17] has remained as one of the highly investigated reactions for generating multifunctional adducts, owing to the mildness of the reaction conditions, the wide application scope and the high variability (four diversity points) associated with it. Moreover, it provides an opportunity for a myriad of postmodifications depending on the functional groups introduced during the MCR, thus leading to the synthesis of several pharmacologically important heterocyclic scaffolds, mostly in two operational steps.

Our initial attempts were focused on post-Ugi modifications towards the synthesis of azepino- $\mathbf{1}$ and azacino-indoles 2, being important members of the indole containing alkaloid family, as well as for representing as challenging synthetic targets (Scheme 2a) [18]. Moreover, these scaffolds are scarcely investigated, and reports generally deal with multistep processes, which limits the scope and diversity. A cationic gold complex $\mathrm{Au}\left(\mathrm{PPh}_{3}\right) \mathrm{OTf}$, formed in situ by mixing of $\mathrm{Au}\left(\mathrm{PPh}_{3}\right) \mathrm{Cl}$ and AgOTf, turned out to be the best catalyst giving maximum yields of endo-dig cyclized azapinoindoles $\mathbf{1}$. Surprisingly, Ugi substrates containing a terminal alkyne, gave the 7-exo-dig product $\mathbf{2}$, possibly due to a metal carbene intermediate as described by Echavarren and co-workers [12]. Later on, a better cationic gold system, compared to the previous report, was optimized and utilized (Scheme $2 \mathrm{~b}$ ) [19]. The new protocol allows the synthesis of indoloazocinones $\mathbf{3}$ bearing sterically hindered substituents on the alkyne, which was not possible to achieve using the previously reported protocol. In addition, a comparative study of the new reaction conditions with the previously reported $\mathrm{Au}$ $\left(\mathrm{PPh}_{3}\right) \mathrm{Cl}$ /AgOTf-catalyzed hydroarylation [18] was also performed. In most cases, the current protocol proved to be

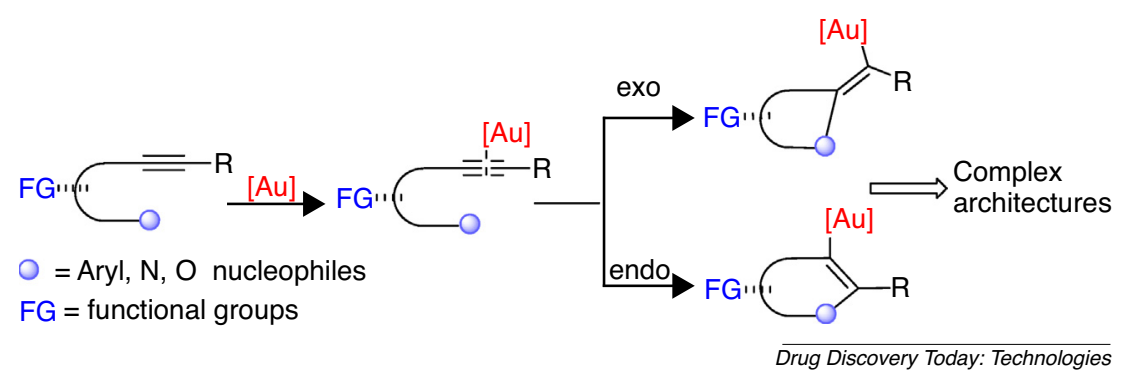

Scheme I. A general scheme for gold catalyzed cyclizations. 


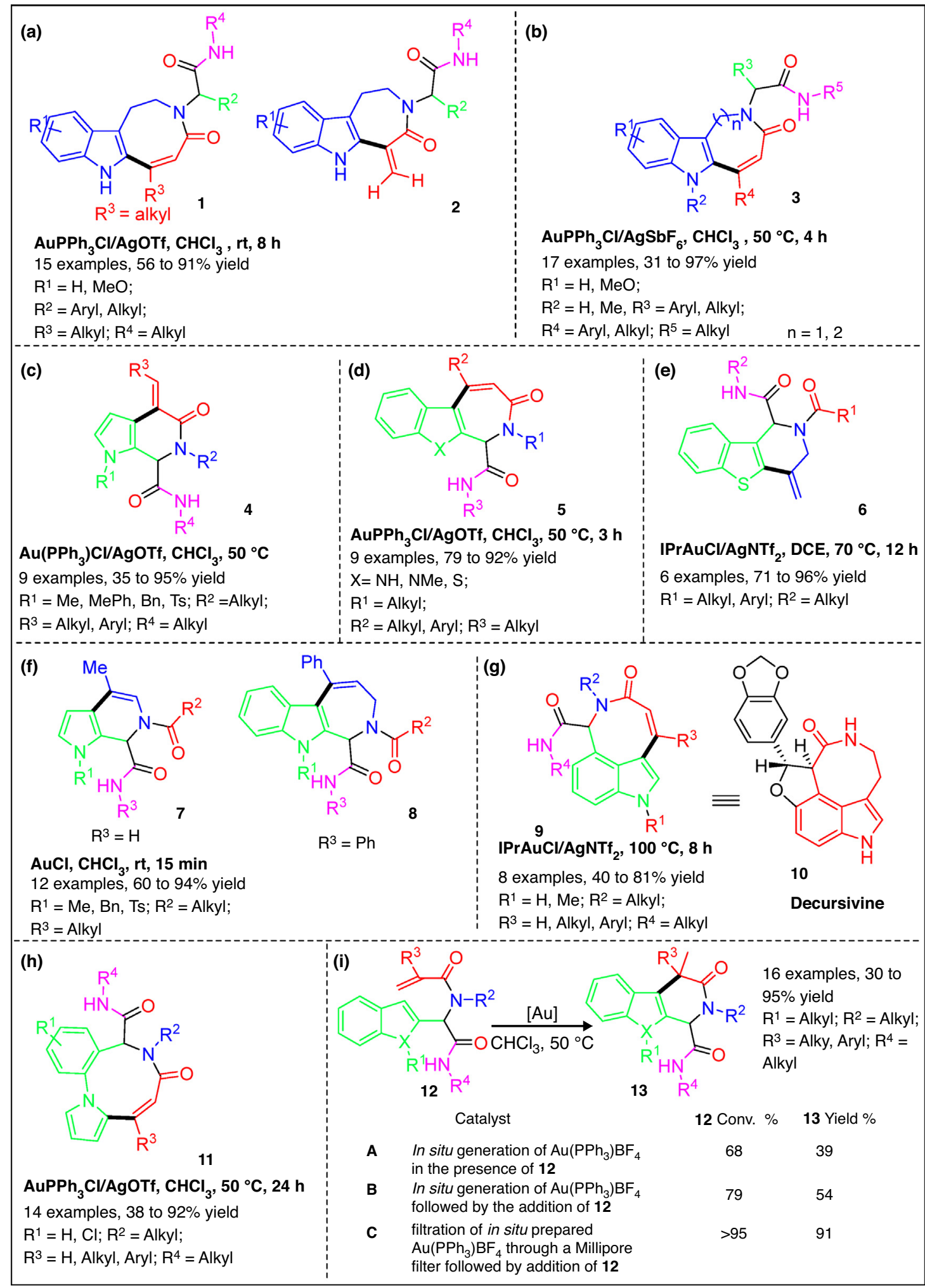

$\overline{\text { Drug Discovery Today: Technologies }}$

Scheme 2. Post-Ugi construction of different heterocycles via gold catalysis. Color represent different Ugi starting material viz. aldehyde (green), amine (blue), acid (red) and isocyanide (pink). 
superior, delivering the desired indoloazocinones $\mathbf{3}$ with improved yields.

Fused heterocyclics with small to medium-sized rings have always remained a widely studied class of biologically interesting molecules. Intermolecular gold-catalyzed reactions of pyrroles usually lack selectivity and a less pronounced selectivity switch has been observed in the related furan cyclizations with gold- and platinum-catalysis [8]. Towards this end, Modha et al. [20] developed a regioselective approach for the synthesis of pyrrolopyridinones employing an Ugi reaction followed by a gold(I)- or platinum(II)-catalyzed intramolecular hydroarylation. Use of cationic gold $\mathrm{Au}\left(\mathrm{PPh}_{3}\right) \mathrm{Cl} / \mathrm{AgOTf}$ gave $100 \%$ conversion to exo-dig cyclized product $\mathbf{4}$ (Scheme 2c). Thereafter, a detailed study of the scope of these protocols employing different heterocycles such as benzothiophene and indole, was reported (Scheme 2d) [21,22]. Interestingly, when the Ugi adduct generated from the reaction of 3-formyl benzothiophene with 2-propynylamine, 2phenylacetic acid, and tert-butyl isonitrile was employed, IPrAuCl/AgNTf $f_{2}$ scores over $\mathrm{Au}\left(\mathrm{PPh}_{3}\right) \mathrm{Cl} / \mathrm{AgOTf}$ for a selective exo-dig cyclization to give benzothienopyridines 6 (Scheme 2e) [22].

Further, aiming to develop milder conditions for such transformations, Kumar et al. [23] described gold(I)-catalyzed post-Ugi hydroarylation towards the synthesis of biologically important heterocycles such as pyrrolopyridines $\mathbf{7}$, pyridoindoles, and azepinoindoles 8 at rt within $15 \mathrm{~min}$ (Scheme 2f). The Ugi adduct was subjected to intramolecular hydroarylation with different gold catalysts $\left(\mathrm{AuCl}, \mathrm{AuCl}_{3}, \mathrm{AuPPh}_{3} \mathrm{Cl} /\right.$ AgOTf, $\mathrm{AuPPh}_{3} \mathrm{Cl} / \mathrm{AgSbF}_{6}$ ), where $\mathrm{AuCl}$ stands out with maximum conversion. In case of phenyl-substituted alkynes or the presence of a tosyl group on the pyrrole nitrogen, no product formation was observed. When indole Ugi adducts bearing a phenyl-substituted alkyne were treated under the optimized conditions, endo cyclized azepinoindoles $\mathbf{8}$ were exclusively formed. 3,4-Fused tricyclic indole based natural products that contain a tricyclic azepino- or azocino- $[c, d]$ indolone core $\mathbf{9}$ have emerged as interesting targets due to their intriguing biological activities and molecular architectures. They are exemplified by the indole alkaloid decursivine 10. Kumar et al. [24] envisaged that a gold-catalyzed post-Ugi regioselective intramolecular hydroarylation reaction could provide an expedient access to the azocino- $[c, d]$ indolone system 9 employing cationic IPrAuCl/AgNTf 2 (Scheme $2 \mathrm{~g}$ ). The application of $\mathrm{AuCl}_{3}, \mathrm{AuCl}$ and $\mathrm{AgNTf}_{2}$ gave almost no conversion.

Most of the literature described here deals with the postMCR construction of six to eight-membered rings via gold catalysis. However, in one typical example, our group [25] has disclosed a highly efficient approach for the regioselective construction of fused nine-membered rings (diazoninone framework) $\mathbf{1 1}$ employing $\mathrm{Au}\left(\mathrm{PPh}_{3}\right) \mathrm{Cl} / \mathrm{AgOTf}$ (Scheme $2 \mathrm{~h}$ ). Other gold-catalyst viz. $\mathrm{Au}\left(\mathrm{PPh}_{3}\right) \mathrm{Cl} / \mathrm{AgSbF}{ }_{6}, \mathrm{Au}\left(\mathrm{PPh}_{3}\right) \mathrm{Cl} /$
$\mathrm{AgNTf}_{2}$, or $\mathrm{Au}$ (X-Phos)Cl/AgOTf did not improve the yield, while almost no conversion occurred with $\mathrm{AuCl}_{3}, \mathrm{Au}\left(\mathrm{PPh}_{3}\right)$ $\mathrm{Cl}, \mathrm{AgBF}_{4}$, and AgOTf.

Recently, an amide remote-controlled stereoselective synthesis of pyrido[3,4-b]indoles $\mathbf{1 3}$ through post-Ugi gold-catalyzed hydro-heteroarylation has been realized employing Ugi 4-component reaction (Ugi-4CR) and further modification by freshly prepared $\mathrm{Au}\left(\mathrm{PPh}_{3}\right) \mathrm{Cl} / \mathrm{AgSbF}_{6}$ (Scheme 2i) [26]. Replacing the $\mathrm{SbF}_{6}{ }^{-}$counter ion with $\mathrm{BF}_{4}{ }^{-}$enhanced the reaction performance. The stereochemistry of the product was confirmed by a NOESY experiment. To determine the effect of silver on this gold-catalyzed hydro-heteroarylation, the reaction was examined under different catalytic conditions, revealing that filtration of in situ prepared $\mathrm{Au}\left(\mathrm{PPh}_{3}\right) \mathrm{Cl} / \mathrm{AgBF}{ }_{4}$ is an important step, resulting in a maximum yield of the desired product.

In addition to the Ugi reaction, which has been used quite frequently for the generation of suitable substrates for goldcatalyzed post-MCR modifications, a few other multicomponent reactions have also been reported to generate suitable skeletons for such transformations. In one such example, Sarkar et al. [27] reported the two-step synthesis of diversely substituted pyrrolo[1,2-a]quinolines 18 that involves an Iron(III)-catalyzed MCR for the synthesis of substituted $N$-(2-alkynylaryl) pyrroles $\mathbf{1 7}$ followed by a gold(III)-catalyzed intramolecular hydroarylation of the alkyne moiety (Scheme 3a). Similarly, Xiao et al. [28] have examined the three-component reaction of benzaldehyde 19, aniline 20, and phenylacetylene 21 with $\mathrm{AuCl}_{3}$ as a catalyst. During initial studies, the reaction afforded two products: propargyl amine $\mathbf{2 2}$ and quinoline derivatives $\mathbf{2 3}$. The formation of quinoline derivatives suggested that further transformation of the propargyl amine by gold catalysis $\left(\mathrm{AuCl}\right.$ or $\left.\mathrm{AuCl}_{3}\right)$ was indeed possible under these reaction conditions (Scheme 3b).

\section{$\mathbf{C}-\mathbf{N}$ and $\mathbf{C}-\mathrm{O}$ bond forming reactions}

In addition to gold-catalyzed $\mathrm{C}-\mathrm{C}$ bond formations, $\mathrm{C}-\mathrm{N}$ and $\mathrm{C}-\mathrm{O}$ bond forming reactions have seen considerable advancement in the last decades. These reactions have proceeded in the same manner as described before, with gold catalyst in combination with various co-catalyst or additives. In one report, Gupta et al. [29] developed a chemoselective cycloisomerization processes using an orthogonal set of gold catalysts, leading to the generation of an array of $\mathrm{N}$-[1,3] oxazino[3,4-a]indol-1-ylideneamine derivatives 28 and pyrimido[1,6-a]indolone derivatives 29 from a common intermediate $\mathbf{2 7}$ (Scheme 3c). The cyclic imidate is a useful synthetic building block and an important pharmacophore. Pyrimido[1,6-a]indolones 29 have importance in medicinal chemistry as 5-HT3 receptor antagonists, topoisomerase II inhibitors and fluorescent materials. The first step is the annulation of 2-(2,2-dibro- 


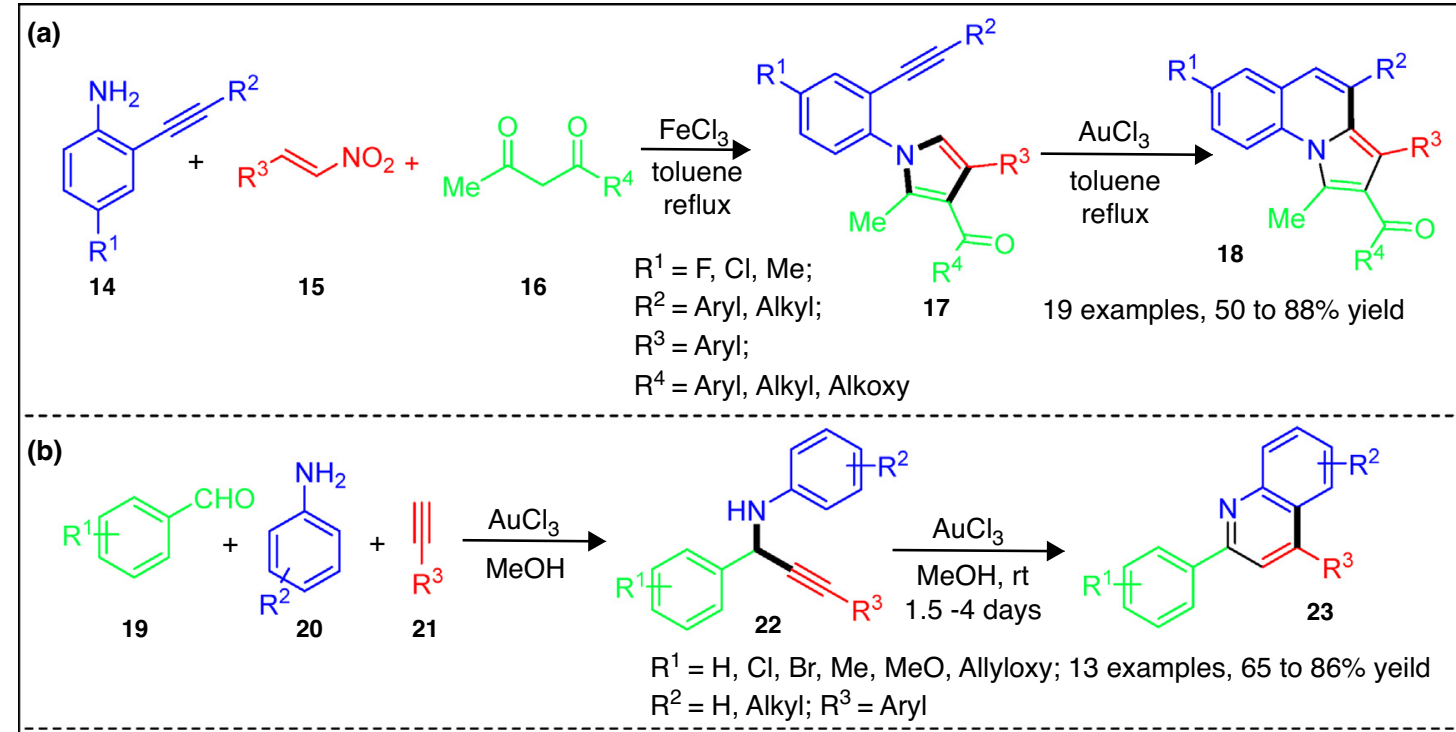

(c)

12 examples $33-89 \%$ yield

$\mathrm{R}^{4}=\mathrm{H}$, Alkyl, Aryl; $\mathrm{R}^{5}=$ Alkyl

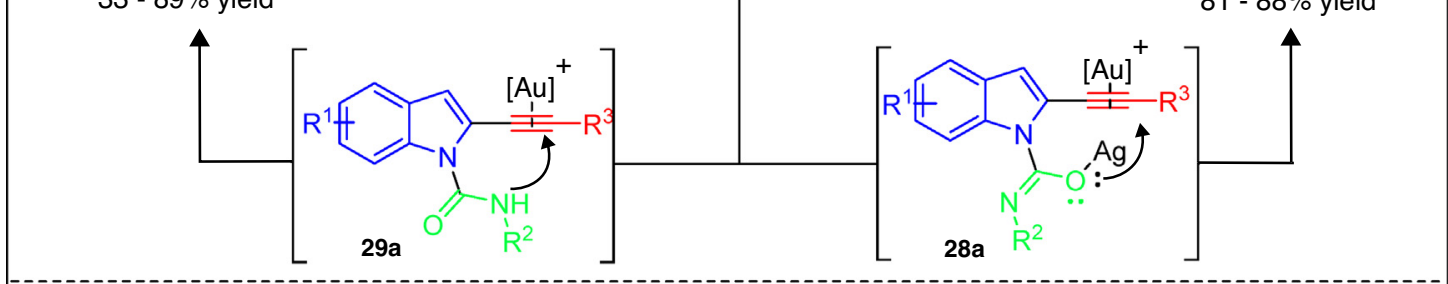<smiles>[Y6]Nc1cc[R1]cc1C=C(Br)Br</smiles><smiles>[R]C#C[NH2+]N=C=O</smiles>
$\mathrm{R}^{1}=\mathrm{H}, \mathrm{Cl}, \mathrm{OCH}_{2} \mathrm{O}$; MCR $\mathrm{Pd} / \mathrm{C}, \mathrm{Cul}$
$\mathrm{R}^{2}=\mathrm{R}^{3}=$ Alkyl, Aryl

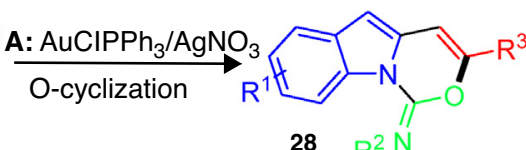

12 examples $81-88 \%$ yield<smiles>[R]NC(=O)C1c2c([R])nc([R])n2C([R])=CC(=O)N1[R]</smiles>

$\mathrm{Au}\left(\mathrm{PPh}_{3}\right) \mathrm{Cl} / \mathrm{AgBF}_{4}, \mathrm{CHCl}_{3}, 70^{\circ} \mathrm{C}$

18 examples, 68 to $98 \%$ yield

$\mathrm{R}^{1}=\mathrm{R}^{2}=\mathrm{H}, \mathrm{Me} ; \mathrm{R}^{3}=$ Alkyl;

(d)<smiles>[R]NC(=O)C([R])N1CCOC([R])=CC1=O</smiles>

$\mathrm{AuPPh}_{3} \mathrm{Cl} / \mathrm{AgOTf}, \mathrm{CHCl}_{3}, 2{ }^{\circ} \mathrm{C}, \mathbf{2 - 4} \mathrm{h}$

8 examples, $64-89 \%$

$\mathrm{R}^{1}=$ Alkyl;

$R^{2}=$ Alkyl, Aryl; $R^{3}=$ Alkyl

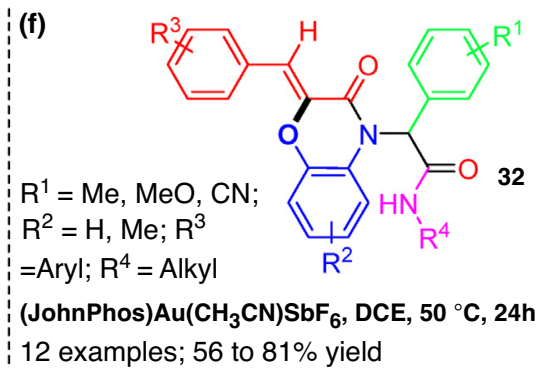

Drug Discovery Today: Technologies

Scheme 3. Different MCRs and gold-catalyzed post modifications towards $C-C$ bond formations $(a-c)$ towards $C-N$ bond formations ( $c-f$ )

movinyl)aniline $\mathbf{2 4}$, an isocyanate $\mathbf{2 5}$, and a terminal alkyne 26 in a three-component tandem format via $\mathrm{Cu}$ / Pd-catalyzed cross-coupling, to afford $\mathrm{N}-1$ and $\mathrm{C}-2$ functionalized indole $\mathbf{2 7}$. In the subsequent step, the enyne-urea derivative undergoes chemo- and regioselective 6-endo cyclization to afford $O$-cyclized product in the presence of $\mathrm{AuClPPh} / \mathrm{AgNO}_{3}$, and $\mathrm{N}$-cyclized product in the presence of $\mathrm{AuClPPh}_{3} / \mathrm{AgOTf}$. Mechanistically, the ni- trogen of the urea, being less electronegative than oxygen, favorably attacks as a relatively softer nucleophile onto the electron-deficient alkyne to afford $\mathrm{N}$-cyclized product $\mathbf{2 9}$, a phenomenon that could be well explained following HSAB theory. In contrast, $O$-cyclization might be promoted via intermediate $\mathbf{2 8} \mathbf{a}$ involving activation of the alkyne by gold-catalyst along with coordination of silver with the oxygen of the urea to furnish $\mathbf{2 8}$. 
The imidazodiazepinone core is ubiquitous in various natural products and pharmaceuticals (bretazenil, flumazenil etc.). It it a vital intermediate in the synthesis of pentostanin and coformycin, both naturally occurring anticancer and antiviral nucleosides [30]. In this direction, Kumar et al. have developed an expedient post-Ugi intramolecular heteroannulation approach for the synthesis of imidazodiazepinones 30 employing gold catalysis (Scheme 3d) [31].

Similarly, procedures for the synthesis of O-containing medium-ring heterocycles are of particular importance owing to their widespread occurrence in natural products and biologically active compounds. Peshkov et al. [32] established a general and selective entry towards the oxazepine scaffold $\mathbf{3 1}$ (Scheme 3e) employing gold catalysis. The in situ generated cationic gold complex $\mathrm{Au}\left(\mathrm{PPh}_{3}\right) \mathrm{Cl} / \mathrm{AgOTf}$ led to the full conversion of hydroxypropargylamide substrates within $2 \mathrm{~h}$ at rt, forming the desired oxazepines $\mathbf{3 1}$ in good to excellent yields. Recently, Singh et al. [33] have realized a gold catalyzed 6-exo-dig cyclization for the synthesis of benzoxazinones $\mathbf{3 2}$ from Ugi adducts. The precursors were first synthesized via an Ugi reaction followed by a reaction with Echavarren's gold(I) catalyst [JohnPhosAu $\left.\left(\mathrm{CH}_{3} \mathrm{CN}\right)\right] \mathrm{Cl} /$ $\mathrm{AgSbF}_{6}$ selectively affording benzoxazinone derivatives in moderate to good yields (Scheme 3f).

\section{Post-MCR cascades or domino reactions}

Cascade transformations are step-economical processes resulting in augmented molecular complexity and diversity, starting from simpler molecules. They are often accompanied by a high degree of chemo-, regio-, and diastereoselectivity. Some noteworthy examples from the recent literature employing gold catalysis, have been highlighted in this section.

Spirocyclizations are perceived as an interesting method for generating complex heterocyclic system with built-in stereo- or regioselectivity in most cases. Accessing such alkaloids in a one-pot cascade fashion while securing diversity is highly desirable from a sustainable chemistry perspective. Modha et al. have effectively exploited the catalytic activity of $\pi$-acidic gold salts involving triple bond transformations by disclosing a diversity-oriented approach for the synthesis of fused polycyclic spiroindolinones 34 (Scheme 4a) [34]. The developed post-Ugi, gold(I)-catalyzed diastereoselective domino cyclization process involved a "branched-handed" precyclization architecture resulting from the chiral center present in the Ugi adduct 33. The expected outcome of the reaction was an indoloazepinone through an endo-dig cyclization and rearrangement sequence [18]. Instead, an exo-dig cyclization followed by intramolecular trapping of the spirointermediate occurred, resulting in the diastereoselective formation of a tetracyclic spiroindolinone $\mathbf{3 4}$ (Scheme 4a).

Notably, methyl substitution at the 2-position of the indole core completely inhibited the cyclization, and the starting material was quantitatively recovered. A tosyl group on the indole nitrogen strongly diminished the nucleophilicity of this core and hence no cyclized product could be obtained. The observed diastereoselectivity of the reaction was explained by the mechanism which involves the activation of the triple bond of the Ugi adduct $\mathbf{3 3}$ by cationic gold, followed by a nucleophilic attack (with two possible pathways) of the C-3 position of the indole 33a. Attack from the back side of the indole core would result in intermediate $\mathbf{3 3 \mathbf { b }}$. However, trapping of the intermediate iminium ion by the secondary amide is sterically impossible and might result in ring re-opening. In contrast, when the attack occurs from the front side of the indole 33c intermediate is formed, and trapping of the iminium ion is possible, giving rise to the desired spiroindolinone 34. Later on, another variant of this reaction was developed giving rise to spiroindolines with propargylamines as an alkyne source [35]. The reaction was carried out with one equivalent of trifluoroacetic acid (TFA) to improve the yield. The authors suggested that, apart from being a good proton source, TFA might act as a co-ligand in this spirocyclization reaction.

Fused azaspiro tetracyclic $N$-heterocycles are prominent molecular motifs that are widely present in different alkaloids such as (+)-plicamine, (+)-tazettine and (+)-erysotramidine with a plethora of biological activities. The gold-catalyzed dearomatization/ipso-cyclization of phenols has attracted a lot of attention due to its unique capacity to generate highly functionalized spirocarbocycles [36]. In this direction, He et al. [37] have reported a gold(I)-catalyzed post-Ugi domino dearomatization/ipso-cyclization/aza-Michael sequence to construct diverse and complex fused azaspiro tetracyclic scaffolds 36 in only two operational steps (Scheme 4b). Different Ugi adducts 35 were synthesized from 4-hydroxy1-naphthaldehyde as a distinctive Ugi substrate, along with amine, isocyanide, and 2-alkynoic acid, and then subjected to the domino cyclization reaction under the optimized conditions. A postulated reaction mechanism involves $\pi$-activation of the triple bond by in situ formed cationic gold(I) species (35a) followed by nucleophilic attack at the C-4 position of 1naphthol in a 5-exo-dig fashion, resulting in the formation of the spirocarbocyclic intermediate $\mathbf{3 5 b}$. Subsequently, azaMichael addition facilitated by $\pi$-activation of the cationic gold species, generates the tetracyclic scaffold 36 .

Very recently, in continuation of this idea, He et al. [38] developed an efficient gold(I)-catalyzed post-Ugi domino dearomatization/ipso-cyclization/Michael sequence towards a library of diverse (hetero)-arene-annulated polyheterocycles (Scheme 4c). Screening of various gold complexes, showed that $\mathrm{Au}(\mathrm{IPr}) \mathrm{Cl} / \mathrm{AgOTf}$ gave the highest yield of the desired product at $\mathrm{rt}$. The reaction proceeded well not only with aliphatic, but also with aromatic isonitriles which was unprecedented in most of the previous reports on such postUgi chemical transformations. Mechanistically, an in situ generated cationic gold(I) species activates the triple bond 


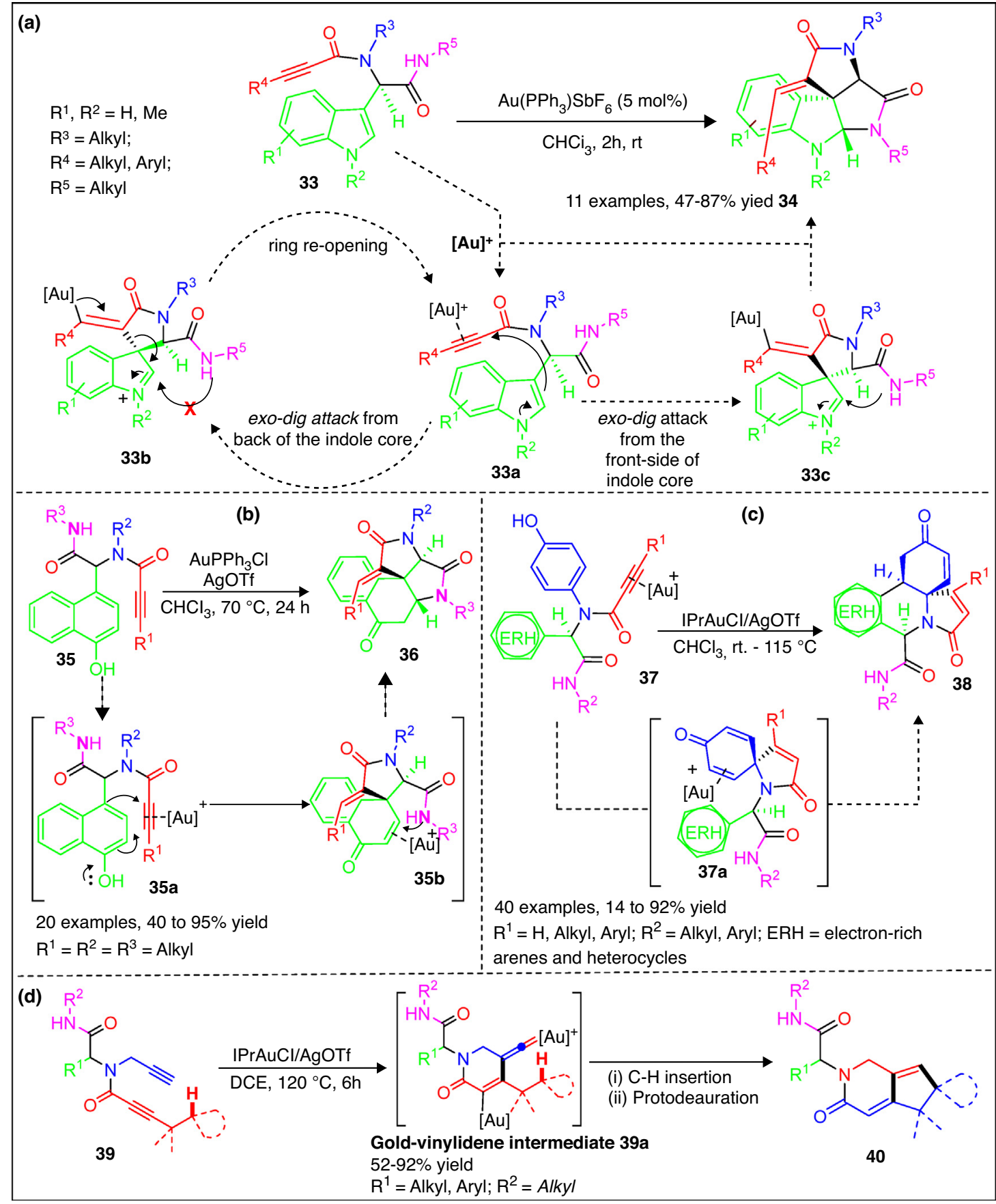

$\overline{\text { Drug Discovery Today: Technologies }}$

Scheme 4. Gold(I)-catalyzed post-MCR regioselective cascade cyclizations towards (spiro)polyheterocycles.

of the Ugi adduct 37. Then nucleophilic attack of the phenol on the activated triple bond occurs in a 5-endo-dig fashion, resulting in the regioselective formation of the spirocarbocyclic intermediate 37a. Subsequently, Michael addition of the indole moiety to the newly formed cyclohexadienone is facilitated by $\pi$-activation by the gold species, resulting in the formation of the final product $\mathbf{3 8}$.

Moving to other interesting methodologies designed by the combination of gold catalysis and post-MCR rigidifica- tion strategies, an interesting dual $\sigma-\pi$ activation by gold catalysis towards post-Ugi transformations was reported [39]. $\mathrm{Au}(\mathrm{IPr}) \mathrm{Cl} / \mathrm{AgOTf}$ efficiently catalyzed the regioselective cascade cyclization of $\mathrm{N}$-propynylbutynamide 39 via $\mathrm{C}_{\mathrm{sp}} 3-\mathrm{H}$ functionalization for the synthesis of (spiro)cyclopentapyridinones $\mathbf{4 0}$ (Scheme 4d). Mechanistically, the first step is the formation of gold-acetylide which upon $\pi$-activation of the butynamide, directs the 6-endo-dig-cyclization, resulting in the formation of the gold-vinylidene intermediate $\mathbf{3 9 a}$. This 
highly reactive species may undergo facile $\mathrm{C}-\mathrm{H}$ insertion, which upon protodeauration forms the final product $\mathbf{4 0}$ (Scheme 4d).

\section{Summary and future outlook}

Until recently, Pd-catalyzed (hetero)annulations mostly occupied the front seat in post-MCR transformation chemistry, with most efforts made towards post-Ugi/Heck modifications and arylation approaches as described in our previous review on the topic [3]. The development of novel transformations for generating synthetically challenging structures via tuning of the gold catalytic system, along with suitable substrates, has opened new doors for the synthesis of diverse heterocyclic scaffolds. Consequently, this review, highlights and discusses the rise of gold-catalyzed post-MCR transformations as an emerging field. Therefore, it would help researchers to better understand the chemistry behind this, and stimulates them to develop better synthetic methodologies.

\section{Acknowledgements}

UKS is thankful to the University of Leuven (KU Leuven) for providing postdoctoral research associateship. GT is thankful to the China Scholarship Council for obtaining a PhD scholarship. The publication was prepared with the support of the "RUDN University Program 5-100".

\section{References}

[1] Zhu J, Bienaymé H. Multicomponent reactions. Weinheim: Wiley VCH; 2005.

[2] Ruijter E, Scheffelaar R, Orru RV. Multicomponent reaction design in the quest for molecular complexity and diversity. Angew Chem Int Ed 2011;50:6234-46.

[3] Sharma UK, Sharma N, Vachhani DD, Van der Eycken EV. Metal-mediated post-Ugi transformations for the construction of diverse heterocyclic scaffolds. Chem Soc Rev 2015;44:1836-60.

[4] Dömling A. Recent developments in isocyanide based multicomponent reactions in applied chemistry. Chem Rev 2006;106:17-89. and references cited therein.

[5] Nakamura I, Yamamoto Y. Transition-metal-catalyzed reactions in heterocyclic synthesis. Chem Rev 2004;104:2127-98.

[6] D'Souza DM, Müller TJJ. Multi-component syntheses of heterocycles by transition-metal catalysis. Chem Soc Rev 2007;6:1095-108.

[7] Kumar A, Singh S, Sharma SK, Parmar VS, Van der Eycken EV. Goldcatalyzed cyclization processes: pivotal avenues for organic synthesis. Chem Rec 2016;16:73-83.

[8] Hashim ASK. Gold-catalyzed organic reactions. Chem Rev 2007;107:3180211.

[9] Corma A, Leyva-Pérez A, Sabater MJ. Gold-catalyzed carbon-heteroatom bond-forming reactions. Chem Rev 2011;111:1657-712.

[10] Stratakis M, Garcia H. Catalysis by supported gold nanoparticles: beyond aerobic oxidative processes. Chem Rev 2012;112:4469-506.

[11] Gorin DJ, Sherry BD, Toste FD. Ligand effects in homogeneous Au catalysis. Chem Rev 2008;108:3351-78.

[12] Dorel R, Echavarren AM. Gold(I)-catalyzed activation of alkynes for the construction of molecular complexity. Chem Rev 2015;115:9028-72.

[13] Kochanowska-Karamyan AJ, Hamann MT. Marine indole alkaloids: potential new drug leads for the control of depression and anxiety. Chem Rev 2010;110:4489-97.

[14] Fan H, Peng J, Hamann MT, Hu JF. Lamellarins and related pyrrole-derived alkaloids from marine organisms. Chem Rev 2008;108:264-87.
[15] Peshkov VA, Pereshivko OP, Van der Eycken EV. Synthesis of azocino[5,4b] indoles via gold-catalyzed intramolecular alkyne hydroarylation. Adv Synth Catal 2012;354:2841-8.

[16] Donets PA, Hecke KV, Meervelt LV, Van der Eycken EV. Efficient synthesis of the indoloazocine framework via intramolecular alkyne carbocyclization. Org Lett 2009;11:3618-21.

[17] Ugi I. The $\alpha$-addition of immonium ions and anions to isonitriles accompanied by secondary reactions. Angew Chem Int Ed Engl 1962;1:820.

[18] Modha SG, Vachhani DD, Jacobs J, Meervelt LV, Van der Eycken EV. A concise route to indoloazocines via a sequential Ugi gold-catalyzed intramolecular hydroarylation. Chem Commun 2012;48:6550-2.

[19] Vachhani DD, Kumar A, Modha SG, Sharma SK, Parmar VS, Van der Eycken EV. Diversely substituted indoloazepinones and indoloazocinones: a post-Ugi gold-catalyzed regioselective carbocyclization approach. Synthesis 2015;47:1337-47.

[20] Modha SG, Kumar A, Vachhani DD, Sharma SK, Parmar VS, Van der Eycken EV. Gold(I) and platinum(II) switch: a post-Ugi intramolecular hydroarylation to pyrrolopyridinones and pyrroloazepinones. Chem Commun 2012;48:10916-18.

[21] Kumar A, Vachhani DD, Modha SG, Sharma SK, Parmar VS, Van der Eycken EV. Post Ugi gold(I)- and platinum(II)-catalyzed alkyne activation: synthesis of diversely substituted fused azepinones and pyridinones. Synthesis 2013;45:2571-82.

[22] Li Z, Kumar A, Sharma SK, Parmar VS, Van der Eycken EV. Catalystcontrolled exo/endo selectivity in a post-Ugi intramolecular hydroarylation: synthesis of pyrrolopyridinones, pyrroloazepinones, and benzothienopyridines. Tetrahedron 2015;71:3333-42.

[23] Kumar A, Vachhani DD, Modha SG, Sharma SK, Parmar VS, Van der Eycken EV. Gold(I)-catalyzed post-Ugi hydroarylation: an approach to pyrrolopyridines and azepinoindoles. Eur J Org Chem 2013;2288-92.

[24] Kumar A, Li Z, Sharma SK, Parmar VS, Van der Eycken EV. Switching the regioselectivity via indium(III) and gold(I) catalysis: a post-Ugi intramolecular hydroarylation to azepino- and azocino- $[c, d]$ indolones. Chem Commun 2013;49:6803-5

[25] Li Z, Kumar A, Vachhani DD, Sharma SK, Parmar VS, Van der Eycken EV. Regioselective synthesis of diversely substituted diazoninones through a post-Ugi gold-catalyzed intramolecular hydroarylation process. Eur J Org Chem 2014;2084-91.

[26] Butani HH, Vachhani DD, Bhoya UC, Shah AK, Van der Eycken EV. Remote amide-controlled gold-catalyzed stereoselective hydroheteroarylation of acrylamides: access to pyrido[3,4-b]indoles. Eur J Org Chem 2015;2124-8.

[27] Sarkar S, Bera K, Jalal S, Jana U. Synthesis of structurally diverse polyfunctional pyrrolo [1,2-a]quinolines by sequential iron-catalyzed three-component coupling and gold-catalyzed hydroarylation reactions. Eur J Org Chem 2013;6055-61.

[28] Xiao F, Chen Y, Liu Y, Wang J. Sequential catalytic process: synthesis of quinoline derivatives by $\mathrm{AuCl}_{3} / \mathrm{CuBr}$-catalyzed three-component reaction of aldehydes, amines, and alkynes. Tetrahedron 2008;64:2755-61.

[29] Gupta S, Koley D, Ravikumar K, Kundu B. Counter ion effect in Au/Agcatalyzed chemoselective 6-endo-dig $N$ - and $O$-cyclizations of enyne-urea system: diversity-oriented synthesis of annulated indoles. J Org Chem 2013;78:8624-33.

[30] Hawkins LD, Hanvey JC, Boyd Jr FL, Baker DC, Showalter HDH. Inhibitors of adenosine deaminase: synthesis of coformycin and $3^{\prime}$ deoxycoformycin. Nucleosides Nucleotides 1983;2:479-94.

[31] Kumar A, Li Z, Sharma SK, Parmar VS, Van der Eycken EV. An expedient route to imidazo 1,4 diazepin-7-ones via a post-Ugi gold-catalyzed heteroannulation. Org Lett 2013;15:1874-7.

[32] Peshkov AA, Nechaev AA, Pereshivko OP, Goeman JL, Van der Eycken J, Peshkov VA, et al. Gold- and silver-catalyzed 7-endo-dig cyclizations for the synthesis of oxazepines. Eur J Org Chem 2015;4190-7.

[33] Singh K, Malviya BK, Roy TK, Mithu VS, Bhardwaj VK, Verma VP, et al. Catalyst-controlled structural divergence: selective intramolecular 7-endodig and 6-exo-dig post-Ugi cyclization for the synthesis of benzoxazepinones and benzoxazinones. J Org Chem 2018;83:57-68. 
[34] Modha SG, Kumar A, Vachhani DD, Jacobs J, Sharma SK, Parmar VS, et al. A diversity-oriented approach to spiroindolines: post-Ugi gold-catalyzed diastereoselective domino cyclization. Angew Chem Int Ed 2012;51:9572-5.

[35] Kumar A, Vachhani DD, Modha SG, Sharma SK, Parmar VS, Van der Eycken EV. Post-Ugi gold-catalyzed diastereoselective domino cyclization for the synthesis of diversely substituted spiroindolines. Beilstein J Org Chem 2013;9:2097-102.

[36] Wu WT, Xu RQ, Zhang L, You SL. Construction of spirocarbocycles via goldcatalyzed intramolecular dearomatization of naphthols. Chem Sci 2016;7:3427-31. and the references cited therein.
[37] He Y, Li Z, Tian G, Song L, Meervelt LV, Van der Eycken EV. Goldcatalyzed diastereoselective domino dearomatization/ipso-cyclization/ aza-Michael sequence: a facile access to diverse fused azaspiro tetracyclic scaffolds. Chem Commun 2017;53:6413-6.

[38] He Y, Li Z, Robeyns K, Meervelt LV, Van der Eycken EV. A Gold-catalyzed domino cyclization enablingrapid construction of diverse polyheterocyclic frameworks. Angew Chem Int 2018;57:272-6.

[39] Vachhani DD, Galli M, Jacobs J, Meervelt LV, Van der Eycken EV. Synthesis of (spiro)cyclopentapyridinones via $\mathrm{C}_{\mathrm{sp}}{ }^{3}-\mathrm{H}$ functionalization: a post-Ugi gold-catalyzed regioselective tandem cyclization. Chem Commun 2013;49:7171-3. 